\title{
XCII. Essay towards a natural classification of simple bodies
}

\section{Ampere}

To cite this article: M. Ampere (1816) XCII. Essay towards a natural classification of simple bodies, Philosophical Magazine Series 1, 47:218, 438-446, DOI: 10.1080/14786441608628503

To link to this article: http://dx.doi.org/10.1080/14786441608628503

曲 Published online: 27 Jul 2009.

Submit your article to this journal $ऍ$

Џll Article views: 3

Q View related articles $\sqsubset$ 
and obliging attention, and the interest which you evince for the Haytians.

The precious discovery of raccination is too important to human life, and does too much honour to humanity, not to induce me to adopt it in my kingdom. On the arrival of Mr. Prince Sanders, I put vaccination in use with a view to make it generally followed by the Haytian practitioners;-we have an innumerable quantity of children to vaccinate.

It is my intention to give every possible latitude to the happy results of this immortal discovery, which $I$ had not hitherto been able to put in practice in consequence of the disappointment which I met with in the applications I made at Jamaica, St. Thomas, and in the United States of America, relative to this object, the salutary effects of which I am well acquainted with. This benefit will still add to the gratitude of the Haytians for the great and magnanimous British nation.

I have charged Mr. Prince Sanders to testify to you personally my sincere thanks.

(Signed) HENR,

XCII. Essay towards a natural Classification of simple Bodies. By $M$, AMPER R*

$W_{\text {HEN the arbitrary hypotheses which had long led cliemists }}$ astray were hanished from science, and it was ascertained that we were to consider as simple, all the bodies which had not yet been decomposed, the number of these bodies was not twothirds of what they are now: this number successively increased as the processes of chemical analysis were applicd to compounds which had not yet been analysed, or which had been so but imperfectly. Every time that a new simple body was discovered, a further term of comparison was obtained, and new relations were observed: it hecame necessary sometimes to restrain, and sometimes to generalize, the first views of the fathers of modern chemistry; and the want of arranging simple bodies in an order which renders more sensible their mutual relations, and facilitates the study of their properties, becane more and more felt. This order may be purely artificial, like the systematic classifications which were at first resorted to in the other branches of the natural sciences: it may also be deduced from the ensemble of the characters of the bodies which we propose to classify; and by constantly uniting those presented by the most numerous and essential analogies, they will be to chemistry what the natural methods are to botany and zoology.

- Annales de Ckimic et de Physique, tome i, p. 295. March 1816. 


\section{Classification of simple Bodies.}

Hitherto chemists have confined themselves to ranging simple bodies according to the degree of their affinity for oxygen, and the nature of the combinations which they form with it. They ought waturally to have adopted this kind of classification, when they thought that the properties which characterized the oxygen belonged to it in a manner so exclusive that no other body could be associated with it. But nowadays that new facts, and a more accurate interpretation of the facts already known, have rectified whatever was too absolute in the theory established by the celebrated Lavoisier; and now that other substances have presented similar properties; it appears to me that we must of necessity banish from chemistry the artificial classifications, and begin by assigning to each simple body the place which it ought to occupy in the natural order, by comparing it successively with all the rest, and uniting it with those which resemble it by a greater number of common characters, and particularly by the importance of those characters. The first advantage which will result from the employment of such a method, will be to give us a more exact and more complete knowledge of all the properties of simple bodies; and frequently to refer to general laws a multitude of isolated facts. Another advantage will arise from this, namely, that after having ascertained among those which we shall have thus united, analogies so multiplied that we cannot refuse to regard them as connected very closely in the natural order, we shall be led to try upon some, experiments similar to those which have been attempted with success on others. A classification, which should have induced every person from the very origin of modern chemistry to consider all the salifiable bases as belonging to one and the same class of bodies, would have taught chemists to place potash and soda in contact with iron at a high temperature, and potash and soda would have been discovered twenty years sooner. When it was ascertained that chlore was a simple body, it was at first compared to oxygen; and it was only when M. Gay-Lussac remarked its analogies with sulphur, that he was led to a discovery, the consequences of which upon the ulterior progress of chemistry can only as yet be guessed at, siz. that of the chloric and iodic acids, and of the perfect ana logy of the chlorates and iodates with the nitrates. A second approximation followed almost instantly by another discovery to which it naturally led, that of cyanogene, and of the true nature of the hydrocyanic acid. Finally, these very analogies doubtless guided M. Dulong in the work which he communicated to the Institute on the 7 th of November 1815 , in which we see that the oxalic acid is composed of carbonic acid gas and hydrogen gas combined in the ratio of two to one in volume; that Ees

this 
this acid, which he calls in consequence hydro-carbonic acid, conformably to the established nomenclature, is united with the oxides in such a proportion, that the volume of hydrogen which it contains is double that of the oxygen of the oxide, so that when the latter is not very difficult to decompose, water is formed, and the carbonic acid gas remains alone cumbined with the metal, as happens with cyanogene, sulphur, chlore and iode, in the formation of the cyanures, sulphurets, chlorures and iodures.

A third advantage equally important is, to prepare by the natural classification of simple bodies, that of compound substances, -a work of much more labour, and to which I purpose to devote another paper. I know that the compound bodies have been already classen in a manner much more conformable to their true analogies than their elements have been. Many things have doubtless been done in this respect; but more perhaps remains to be dene; and the discovery of the new substances with which the domainte of chemistry have been enriched within these few years, cannot fail to lead to a modification and generalization of the principles according to which we now class compound substances, and to determine in a more precise manner the signification of the names which serve to designate the various kinds of combinations, and particularly that of the words acid, alkali, salt, \&c.

I shall confine myself in this paper to the simple bodies, and shall divide them into three heads. I shall offer in the first, some general considerations on the order according to which it is proper to arrange bodies, so that this order may be as conformable as possible to their natural analogies; and on the means of avoiding the junction which has been hitherto made of the metals with bodies very different in almost all their other characters, and which have only been brought together becallse the energy of their affinity for oxygen is nearly the same,-a circumstance certainly remarkable, but to which perhaps too nuch importance has been attached, $\rightarrow$ and which certain considerations on the natural order of simple bodies, the principal results of which I shall soon detail, ought to induce us to regard as secondary, when it does not concur with other analogies which embrace the whole of the properties of the body.

Under the second head, I shall unite under natural genera the bodies which present characters of resemblance so multiplied and important that it is impossible to separate them in every classification which shall not he purely artificial; and I shall settle at the same time what places ought to be occupied in the natural order by the simple bodies which seem to form the passage from one genus to another, presenting analogies very striking 
with substances belonging to two different genera. In this case, they indicate between these two genera an analogy which it will perhaps be difficult to ascertain without their assistance, but which is not the less real, and according to which we ought to place them in succession after each other, so that the body which establishes the link of the chain is at the end of the first, or the beginning of the second, in order to be always between two bodies which they resemble by common characters. Nothing then remains but to determine with which of the two genera it ought to be definitively united, by comparing the properties which it shares with the one, and those which are common to it with the other, in ordet to decide according to the number and importance of the analogies which result from these properties, The analogies to which these researches will lead us, will fix in an invariable manner the natural order of the simple bodies, conformably to the general idea which I am about to give of them.

The last head of this paper will have for its object to examine once more the various genera into which all these bodies shall have been distributed according to the data lail down in the preceding head, in order to assign to each of them a distinctive character formed by the union of some remarkable properties, chosen in such a way that they cannot be found at once but in a body appertaining to the genus which it is wanted to characterize, and to see at the same time according to what principles of nomenclature we could, if necessary, establish for each genus a denomination common to all the bodies which form part of it.

\section{§ I. On the impossibility of reconciling the manner in which} chemists have hitherto ranged simple bodies, and the distinctions which have been established between them; with a classification deduced from the whole of their properiies; and on the order which it is proper to adopt, to unite as much as possille those which present the most characters in common.

The first source of the artificial classifications hitherto used, seems to me to have arisen from the old distinction of the metals and non-metallic bodies. I must confess, however, that this division leads us to separate but a very sinall number of bodies which we ought to unite in the natural order; and that it is in general tolerably conformable to the classification which results from the comparison of all the properties of bodies; and that it will even be sufficient, in order that it may embrace none of the genera which I regard as natural, to separate from the metals three substances which are generally united with them, arsenic, tellurium, and silicium: but then it becomes very difficult to assign a character which distinguishes in every case the metals 
from the non-metallic bodies. Those which originally bad served as the basis for this distinction can no longer be used as such, since most of the metals hitherto regarded as of that class are brittle; and becatse some have been discovered even lighter than water; and iode, and even carbon, when its particles are very close, as in animal charcoal, present the metalic lustre and a perfect opacity; and because chemists have discovered in earbon the property of being a conductor of the electric fluid, \&c. A more important character, viz. that of producing salifiable bases on being united with oxygen, cannot be considered as sufscient for characterizing exclusively the metals; because some metals do not form any, because the boric and the nitrous acids are combined with the sulpluric acid, and because the products of those combinations have all the characters of the acid salts, which they resemble even more by their easy crystallization than several metallic solutions the oxide of which is precipitated in proportion as they are evaporated; solutions which are only considered as salts, precisely because they are compounded of an acid and of the oxide of a body which we have been accustomed to regard as a metal. This character, which is admitted besides as exclusive, will remove tellurium from arsenic, and particularly from iode; whereas the far more important property which it possesses of forming with hydrogen a permanent acid gas places it necessarily between those two bodies. The first object to which I shall turn my attention in the following article, will be to examine to what extent we might preserve the distinction of the metals, and of the non-metallic bodies, by subjecting the character which we shall choose for defining it in a precise manner, to the modification required by the necessity of rendering it couform to the natural order of simple bodies. I shall confine myself to remarking, that in the way in which it has been admitted, it has retarded the progress of the true theory of chemistry, by inducing a neglect of the observation of the properties by which certain metals are connected with the other simple bodies, and to which we cannot pay too much attention, when it is required to ascertain the truly natural order which exists between both the one and the other. The character drawn from the various degrees of affinity has still more contributed to establish between bodies, and particularly between the metals, approximations disavowed by nature. I shall confine myself to quoting in this respect, an example which appears to me very striking. Silver and gold form equally with oxygen combinations which an elevated temperature easily decomposes: from that instance those two metals have been regarded as being exttitled to be placed very near each other in every methodical arrangement of simple bodics. Nevertheless the degree of affinity 
for chlore ought not, in the eyes of the chemist who has precise ideas as to the action, equally energetic at least with that of oxygen, which it exercises on the metals, to be regarded as a character less important than the degree of affinity for oxygen; and the chlorure of gold is decomposable by heat; whereas that of silver, kept free from the contact of water and hydrogen, is absolutely unalterable at the highest temperature.

Here therefore we have two motives nearly equal, one for uniting and the other for separating these bodies. In order to resolve this difficulty, it is indispensable to have recourse to other properties; those of their oxides and their salts which they form with the acius, are then exhibited naturally, and decide the question, by showing us that the supposed analogy between those two metals is not confirmed by the resemblance of their principal characters. In fact, the oxide of silver is very alkaline, a little soluble in water, and completely saturates the acids: the oxide of gold presents nothing similar: and this difference, added to some other properties, less important, it is true, which silver presents in the metallic state, places this body with lead near potassium and sodium, and consequently very far from gold.

Since presise notions have been acquired as to the nature of chlore, several chemists have ceased to give to the properties which depend on the affinity of simple bodies for oxygen, an exclusive preponderance; but then one too great has been given to the assimilation which has been made of oxygen and of chlore. It has been attempted to arrange all the simple bodies in two classes, independent of each other, under the names of comlustible bodies, and supporters of comlustion. This division has had the same inconvenience with that of the metals and the noninetallic bodies, by making us mistake the analogies of bodies which it places in different classes. This inconvenience has even been the more injurious to the theory of chemistry, in as much as it has taught us to neglect analogies much more complete and more striking than those which the separation of the metals and other simple bod:es had caused to be neglected. Such are the analogies of the chloric and iodic acids with the sulphuric and nitric acids, of the chlorates and the iorlates with the nitrates, and particularly that of chlore and iode with sulphur, greater still than the analogy of the same bodies with exygen. The combination of those four substances with the metals to which they strongly adhere, takes place by occasioning a greater or less extrication of heat, and frequently of light : the compounds which result present a crowd of common properties : so far there is no occasion to approximate more particularly chlors and iode to oxygen than to sulphur; but this last forms like iode 
iode and chlore a permanent acid gas with hydrogen : the hydrasulphates present the greatest analogy with the hydro-iodates and hydro-chlorates: they are reduced into sulphurets, as the latter are into iodures and chlorures, when they are insoluble, of after having evaporated their solutions, and dried their residuesproperties which still more closely approximate jode and chlore to sulphur than to oxygen. It is impossible to separate iode from chlore, from which it differs only because the same characters are manifested at a less degree of energy; and nevertheless, why should iode be a supporter of combustion rather than sulphur, which is united to most of the metals with a greater extrication of light and heat? Shall we say that the sulphur is combined with the oxygen of the atmospheric air when we expose it to a sufficient temperature, and that this is not the case with iode also? But is the latter not also combined with oxygen when we place it in contact with the gaseous oxide of chlore, discovered by the celebrated chemist who was the first to decompose the alkalis, and demonstrate that chlore is a simple body, conformably to the opinion already given by the French chemists as an arlmissible hypothesis? It is of no use to insist longer on considerations of this kind: what precedes is sufficient to show how easy it is to be led into error, and to give too much importance to certain analogies, when we commence by establishing between the bodies which we purpose to classify, general divisions founded on a single character only. We should then deceive ourselves still more, if we thought to be able to arrange the simple bodies in an order conformable to their natural analogies, by forming of them a series dependent on their various. degrees of affinity for one of them, for oxygen for instance. On comparing all the properties which those substances present, we find that they form a system in which every body belongs, on one side or the other, to bodies adjoining them, by analogies so strong that we are not able to establish in any way the complete separation which will be required by the reduction of the system into a single series; so that we must represent it to ourselves as a sort of circle, in which two bodies placed at the two extremities. of the chain formed by all the rest, approach and unite mutually by common characters. I have long endeavoured to establish a natural order amorig simple bodies, by arranging them in a single series, which should commence with those whose properties jresented the most complete opposition to those of the bodies which I attempied to place at the end of the series: these atrempts have not been attended with any success; and it is by them that $I$ have been led to adopt an order quite different, of which I shall in the first place attempt to give a general idea, 
which shall be developed and defined in the two following articles. The bodies which have been hitherto considered as nonmetallic, all possess the property of forming acids with some among them, the distinctive character of which is to make acid all combinations into which they enter in sufficient quantity. Several metals, and even some of those best entitled to this name, also present this property, and produce acids on being combined with the same acidifying substances. Those metals form two groupes, distinguished besides from each other by numerous differences. Some are eminently fixed and infusible; and it seems to be the same case with their combinations with chlore; at least if we may judge by the chlorure of chrome which presented this property to $M$. Dulong. It is with oxygen that they produce the acids from which the chemists have drawn the character which distinguishes them. The others are very fusible; the combinations which they form with oxygen present but feeble acid characters; for we ought not to reckon among them arsenic, which, as I have already said, ought to be united to the bodies which are considered as not metallic. And but for the labours of Messrs. Chevreul and Berzelins, the acidity of the peroxides of tin and antimony would have been still unknown; but these metals produce with chlore compounds liquid, or of a butyraceous consistency and volatile, and which possess the most essential properties of the acids. It is easy to see that the non-metallie simple bodies are united on the one hand with the infusible metals acidifiable by carbon and borium, and on the other with tin and antimony by phosphorus and arsenic, the combinations of which with chlore have the greatest analogy with the chlorostannic acid (spiritus Libavii). All the other metals ought therefore to be placed between tin and antimony on the one hand, and the infusible acidifiable metals on the other. 'Those which add to the greatest affinity for oxygen, the property of forming with it alkaline combinations, occupy in some measure the middle part of this interval, and are connected on the one hand with tin and antirnony, and on the other with tungsten, columbium, chrome, and molybdenum, by two series of metals, which present in the one and the other series all the degrees of affinity for oxygen, and the oxides of which also pass gradually through the various degrees of alkalinity and aeidity which characterize that kind of compounds; but the bodies of which the two series are composed, present besides sufficient differences to eilable us always easily to determine that to which they belong.

Such is the order by which I have been led, not by systematic views, which I disavow; but after having made a great number of attempte, in order to see if we could not adopt anotlier with- 
out wandering from natural analogies, and after having compared simple bodies under every point of view which can be presented by the properties which they possess.

I shall return to the subject in another paper.

XCIII. On the Laws olserved in the Distribution of vegetable Forms. By Alexander Cotent Humbold't*

Botany, long confined to the simple description of the external forms of plants and their artificial classification, now presents several branches of study, which place it more on a footing with the other sciences. Such are the distribution of vegetables according to a natural method founded upon the whole part of their structure; physiology, which displays their internal organization; botanical geography, which assigns to each tribe of plants their height, limits, and climate. 'The terms alpine plants, plants of hot countries, plants of the sea-shore, are to be found in all languages, even in those of the most savage nations on the banks of the Oronoko. They prove that the attention of tnen bas been constantly fixed on the distribution of vegetables, and on their connexion with the temperature of the air, the elevation of the soil, and the nature of the ground which they inhabit. It does not require much sagacity to observe, that on the slope of the high mountains of Armenia, vegetables of a different latitude follow each in succession, like the climates, superposed as it were upon each other. This idea of Tournefort, developed by Linnæus in two interesting dissertations, (Stationes et Colonice Plantarum, nevertheless contains the first seeds of botanical geography. Menzel, the author of an unpublished Flora of $\mathrm{Ja}^{-}$ pan, strongly recommends to travellers researches as to the dis. tribution of species in the different regions of the globe. He had even pointed out the result before by the name of the Geography of Plants. This appellation was again employed, and almost at the same time, about the year 1783 , by the Abbe Giraud Soulavie, and by the celebrated author of the Studies of Nature; a work which, amid a great variety of very inaccurate ideas as to the physique of the globe, contains some profound and ingenious views as to the forms, relations, and habitudes of vegetables. Abbé Giraud Sonlavie was occupied in preference with the plants already cultivated: he has distinguished the climates of the olive trees, the vines, and the chesnuts. He gives a vertical section of Mount Mezin, to which he has added the

\footnotetext{
* Extracted from a paper read to the French Institute, Feb. 5, 1816.
}

harcmetrical 